Research NOTE

\title{
Trichinellosis in mice: effect of albendazole on the glutathione transferase in the intestines
}

\author{
Agnieszka Wojtkowiak-Giera ${ }^{1}$, Elżbieta Wandurska-Nowak ${ }^{1}$, Michał Michalak ${ }^{2}$, Monika Derda ${ }^{1}$ \\ and Jadwiga Lopaciuch ${ }^{1}$
}

${ }^{1}$ Poznan University of Medical Sciences, Department of Biology and Medical Parasitology, Fredry 10, 61-701 Poznan, Poland;

${ }^{2}$ Poznan University of Medical Sciences, Department of Computer Science and Statistics, Dabrowskiego 79, 60-529 Poznan, Poland

\begin{abstract}
The glutathione S-transferases (GSTs) are a family of multifunctional enzymes involved in cellular detoxification. The aim of this study was to evaluate the effect of albendazole - drug of choice for trichinellosis - on the total activity and kinetics of cytosolic GST in the mouse intestines during experimental trichinellosis. Our results showed a statistically significant decrease in the total GST activity both in the small and large intestines of the mice infected with the nematode Trichinella spiralis (Owen, 1835) and treated with albendazole, compared with the control mice that were infected but untreated with the drug. Furthermore, albendazole administration modified the kinetics of substrate saturation of GST in the intestines of the infected mice because the drug caused changes in Michaelis constant values of this enzyme. Based on our observations, we suggest that the quaternary structure of GST from the mouse intestines is impacted by this drug during trichinellosis.
\end{abstract}

Keywords: trichinellosis, mouse intestines, glutathione transferase, albendazole

Trichinellosis, a parasitic disease mainly caused by the nematode Trichinella spiralis (Owen, 1835), can be divided into two phases: an intestinal and a subsequent muscular phase. Following ingestion by a host, parasite larvae actively invade the small intestinal epithelium of the host, where they moult, mature and mate. The females deliver newborn larvae, which are carried by the host's blood and lymphatic vessels to the fibres of skeletal striated muscles, the final habitat of this parasite.

Glutathione S-transferases (GSTs, EC 2.5.1.18) are multifunctional enzymes involved in cellular detoxification and catalysing a variety of reactions. These enzymes catalyse the conjugation of nonpolar compounds with an electrophilic carbon, nitrogen, or sulfur atom to a thiol group of reduced form of glutathione (Wilce and Parker 1994, Sheehan et al. 2001, Hayes et al. 2005, Oakley 2005). It has been suggested that GST participates in the oxygen free radical-based biochemical defense against $T$. spiralis infection (Derda at al. 2001, 2003, Wojtkowiak at al. 2007, Wojtkowiak-Giera at al. 2011).

Albendazole (methyl 5-propylthio-1H-benzimidazol-2-yl carbamate) is a benzimidazole anthelmintic widely used in the treatment of trichinellosis. The anthelmintic activity of benzimidazoles (BZs) is related primarily to their preferential binding to the colchicine-sensitive site of tubulin of helminths over tubulin of mammals. Thus BZs are selectively toxic to the parasitic helminths. It is well known that BZs inhibit the polymerization of parasite $\beta$-tubulin into microtubules impairing structure, integrity and energy metabolism in cells of parasites (Lacey 1990, Köhler 2001). Microtubules are ubiquitous cellular organelles serving a variety of vital functions including mitosis, motility and transport. The depolymerization of cytoplasmic microtubules leads to the impaired uptake of glucose and depletes glycogen stores resulting in the reduction of energy production. In view of the crucial roles these organelles play in many cellular processes, their drug-induced destruction may lead to the death of the organism (Lacey 1988). In this study the effect of albendazole administration on the activity and kinetics of GST was examined in order to verify the idea of a multifunctional mode of action of anthelmintic drugs, including BZs. It is hypothesized that antiparasitic activity of anthelmintics could be enhanced by their effect on host defence mechanisms.

In our previous investigations, we noticed that albendazole administration modified both the activity and kinetics of cytosolic GST in the mouse skeletal muscles during experimental trichinellosis (Derda et al. 2003, Wojtkowiak et al. 2007). In another study, we observed an increase in the total GST activity in the small and large intestines of mice infected with T. spiralis. In addition, we noticed changes in the kinetics of substrate saturation of GST isolated from the mouse intestines during the intestinal phase of trichinellosis (Wojtkowiak-Giera et al. 2011). In this context, our present study was undertaken to examine the effect of albendazole on the total activity and kinetics of cytosolic GST in the mouse intestines during experimental trichinellosis.

The experiments were approved by the local Ethics Committee for Animal Experiments. The experimental material consisted of the small and large intestines of BALB/c mice infected with $T$. spiralis strain MSUS/PO/60/ISS3 and treated with albendazole. Male mice, $8-10$ weeks old with the body weights of 20-25 g, were bred and housed in our animal laboratory, which ensured approximately constant temperature, humidity, circadian light-dark cycles, and free access to standardized, granulated food and water. Mice were inoculated orally with about 400 T. spiralis larvae per mouse in $0.1 \mathrm{ml}$ of phosphate-buffered saline (PBS). Infective larvae were obtained by the pepsin- $\mathrm{HCl}$ 


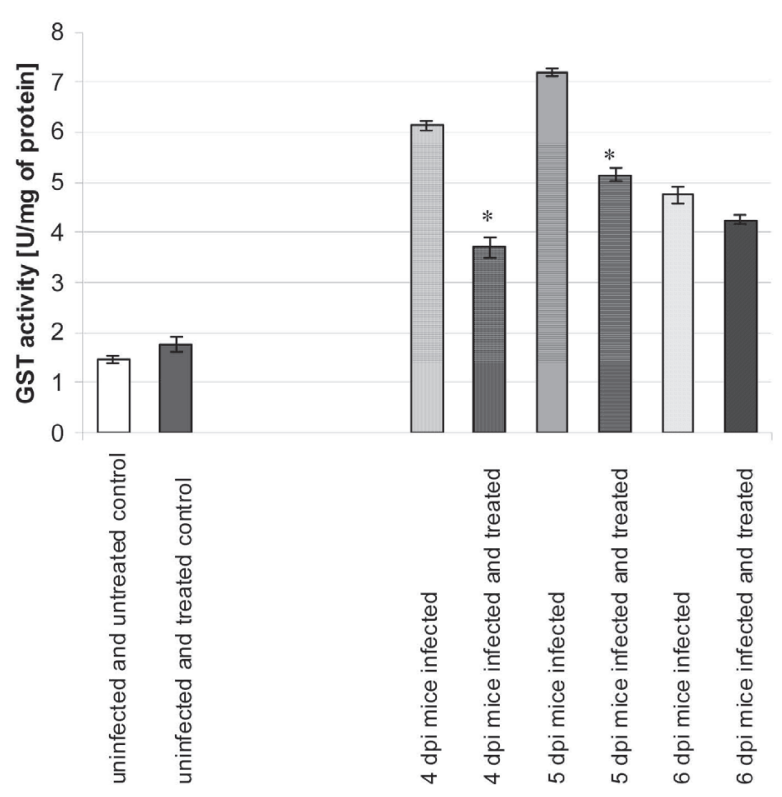

Fig. 1. The activity of GST in the small intestines isolated from mice infected with Trichinella spiralis and treated with albendazole. GST activity was determined with $1 \mathrm{mM} \mathrm{GSH}$ (the reduced form of the glutathione) concentration used as a substrate. The values are expressed as units per milligram of protein. Data represent mean \pm SD and are representative of groups of six animals. ${ }^{*} P<0.01$, compared with the control value derived from infected and untreated mice (Mann-Whitney $U$ test).

digestion of skeletal muscles from mice infected with $T$. spiralis a few months before the experiment began. Albendazole (Zentel, SmithKline, Beecham) was administered orally, twice, on the 2nd and 4th days post infection (dpi), at the dose of $25 \mathrm{mg} / \mathrm{kg}$ of body weight. The resulting intensity of infection in the sixth week pi was about 1600 larvae per gram of muscle in the case of infected mice untreated with drug, and about 600 larvae per gram of muscle in the case of infected mice treated with albendazole. The animals were sacrificed by an intraperitoneal overdose of anaesthesia using $25 \mathrm{mg} / \mathrm{kg}$ ketamine and $2 \mathrm{mg} / \mathrm{kg}$ pethidine hydrochloride.

For experiments, small and large intestines were dissected from mice on 3, 4, 5, 6 and 11 dpi. The experiments were performed twice with three animals per group in each point of measurement. The control mice, which were infected but untreated with albendazole, were examined at all stages of the investigation. The mouse intestines were rinsed with ice-cold PBS. For further studies, two segments of about $2 \mathrm{~cm}$ of the small intestine and two segments of about $1 \mathrm{~cm}$ of the large intestine were isolated. Intestinal 15\% homogenates in PBS were centrifuged at $15000 \mathrm{~g}$ for $30 \mathrm{~min}$, and the obtained supernatants, considered as cytosolic fractions, were used for GST estimation.

The activity of GST was determined spectrophotometrically by monitoring the formation of the thioether (S-2,4-dinitrophenylglutathione) between the reduced form of the glutathione (GSH in the concentrations ranging from 0.2 to $2.0 \mathrm{mM}$ ) and 1-chloro-2,4-dinitrobenzene (1 mM CDNB). Measurements of the conjugation rate, as a function of time, between $\mathrm{CDNB}$ and GSH were performed at $340 \mathrm{~nm}$, according to the procedure of Habig and Jacoby (1981). The activity of GST was expressed in

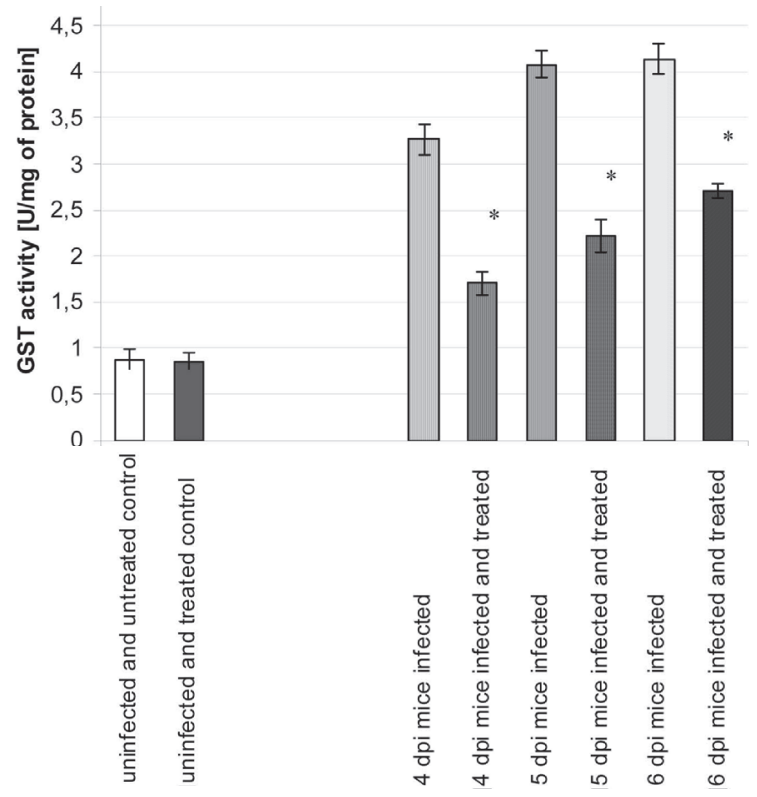

Fig. 2. The activity of GST in the large intestines isolated from mice infected with Trichinella spiralis and treated with albendazole. GST activity was determined with $1 \mathrm{mM} \mathrm{GSH}$ (the reduced form of the glutathione) concentration used as a substrate. The values are expressed as units per milligram of protein. Data represent mean $\pm \mathrm{SD}$ and are representative of groups of six animals. $* P<0.01$, compared with the control value derived from infected and untreated mice (Mann-Whitney $U$ test).

units of enzyme per milligram of protein. One unit of enzyme is defined as the amount catalysing the formation of $1 \mu \mathrm{mol}$ of thioether per minute at $25^{\circ} \mathrm{C}$. The total GST activity was determined with $1 \mathrm{mM}$ GSH concentration used as a substrate.

In order to determine the kinetics of substrate saturation of GST, the following concentrations of GSH were used: 0.2, 0.4, $0.6,0.8,1.0,1.2,1.4,1.6,1.8$ and $2.0 \mathrm{mM}$. Data were plotted as double-reciprocal Lineweaver-Burk plots (1/GST activity as a function of $1 / \mathrm{GSH}$ concentration) to determine the $K_{\mathrm{m}}-$ Michaelis constant - values. $K_{\mathrm{m}}$ is equal to the substrate concentration at which the reaction rate is half its maximal value, and thus, it is a very important characteristic of an enzyme-catalysed reaction.

Protein content in the samples was determined according to the colorimetric methods of Lowry et al. (1951). The mean value and standard deviation were calculated for each point of measurement. Statistical analysis was performed using the Mann-Whitney $U$ test with statistical software Statistica 7.1, and $P<0.01$ was considered to be statistically significant.

At all stages of the investigation $(3,4,5,6$ and $11 \mathrm{dpi})$ we observed a decrease in the activity of cytosolic GST, both in the small and large intestines of the mice infected with $T$. spiralis and treated with albendazole, compared with the infected and untreated control mice. Our results show a statistically significant, about 1.5-fold decrease in the total GST activity in host small intestines dissected on 4 and 5 dpi (Fig. 1), and about 1.8fold decrease in the total GST activity in host large intestines dissected on 4, 5 and 6 dpi (Fig. 2). However, changes in the total GST activity measured on 3 and 11 dpi were not statistically significant. At the same time, the total GST activities in the 
Table 1. Biphasic apparent $K_{\mathrm{m}}$ values for cytosolic glutathione transferase in the small intestines isolated from mice infected with Trichinella spiralis and treated with albendazole, measured on $5 \mathrm{dpi}$. The control values, measured also on $5 \mathrm{dpi}$, obtained from infected and untreated mice.

\begin{tabular}{|c|c|c|c|}
\hline & $\begin{array}{c}K_{\mathrm{m}} \text { values }(\mathrm{mM}) \\
\text { in the low range } \\
\text { of substrate } \\
\text { concentrations } \\
(0.2-0.5 \mathrm{mM} \\
\mathrm{GSH})\end{array}$ & $\begin{array}{l}\text { Disconti- } \\
\text { nuity } \\
\text { (mM GSH) }\end{array}$ & $\begin{array}{c}K_{\mathrm{m}} \text { values }(\mathrm{mM}) \\
\text { in the high range } \\
\text { of substrate concen- } \\
\text { trations } \\
(0.6-2.0 \mathrm{mM} \text { GSH })\end{array}$ \\
\hline $\begin{array}{l}\text { Control small } \\
\text { intestines isolated on } \\
5 \text { dpi from infected } \\
\text { and untreated mice }\end{array}$ & 0.3 & 0.3 & 50.0 \\
\hline $\begin{array}{l}\text { Small intestines iso- } \\
\text { lated on } 5 \text { dpi from } \\
\text { infected and treated } \\
\text { with albendazole } \\
\text { mice }\end{array}$ & 0.3 & 0.3 & 1.6 \\
\hline
\end{tabular}

intestines of the uninfected mice remained unaffected by albendazole (Figs. 1, 2).

Moreover, we observed that albendazole administration modifies GST kinetics of saturation with GSH in the intestines of the infected mice. In the small intestines of the control, infected and untreated mice as well as of the infected and albendazole-treated mice, a double-reciprocal Lineweaver-Burk plot of GST kinetics of saturation with GSH was biphasic, yielding one apparent $K_{\mathrm{m}}$ value for GSH in the low range of substrate concentrations $(0.2-0.5 \mathrm{mM} \mathrm{GSH})$ and a different apparent $K_{\mathrm{m}}$ value for GSH at high concentrations range (0.6-2.0 mM GSH). In the small intestines isolated from the control mice on $5 \mathrm{dpi}$, GST saturation with GSH has a discontinuity, showing the breakpoint in the biphasic double-reciprocal plot, near $0.3 \mathrm{mM} \mathrm{GSH}$. In a region below $0.3 \mathrm{mM} \mathrm{GSH}$, GST saturation in the infected small intestines was linear in a double-reciprocal plot, yielding an apparently high $K_{\mathrm{m}}=50 \mathrm{mM}$; in a region above $0.3 \mathrm{mM}$ GSH, GST saturation yielding an apparently low $K_{\mathrm{m}}=0.3 \mathrm{mM}$. In the small intestines of the infected and drug-treated mice, the $K_{\mathrm{m}}$ value for GSH at a high concentrations significantly decreased to $1.6 \mathrm{mM}$, yielding 31-fold decrease. At the same time, the $K_{\mathrm{m}}$ value for GSH at low concentration and a discontinuity remained unchanged (Table 1).

The Lineweaver-Burk analysis of data for the large intestines isolated on 5 dpi also gave the biphasic double-reciprocal plot of GST saturation with GSH, yielding an apparently high $K_{\mathrm{m}}=25 \mathrm{mM}$ and an apparently low $K_{\mathrm{m}}=0.5 \mathrm{mM}$, and a discontinuity near $0.4 \mathrm{mM} \mathrm{GSH}$. In the large intestines of the infected and drug-treated mice, the $K_{\mathrm{m}}$ value for GSH at high concentrations significantly decreased to $3.1 \mathrm{mM}$, yielding 8 -fold decrease (Table 2). Albendazole administration affects also the GST kinetics of saturation with GSH in the intestines of the uninfected mice (unpublished data).

The results of our previous study (Wojtkowiak-Giera et al. 2011) confirmed the changes both in the total activity of cytosolic GST and in the kinetics of substrate saturation of this enzyme isolated from the small and large intestines during the intestinal phase of experimental trichinellosis in mice. These changes were statistically significant, compared with the uninfected controls, in the mouse small intestine on $5 \mathrm{dpi}$ and in the case of the mouse large intestine on 6 dpi. Trichinellosis in the mouse small
Table 2. Biphasic apparent $K_{\mathrm{m}}$ values for cytosolic glutathione transferase in the large intestines isolated from mice infected with Trichinella spiralis and treated with albendazole, measured on $5 \mathrm{dpi}$. The control values, measured also on $5 \mathrm{dpi}$, obtained from infected and untreated mice.

\begin{tabular}{|c|c|c|c|}
\hline & $\begin{array}{c}K_{\mathrm{m}} \text { values }(\mathrm{mM}) \\
\text { in the low range } \\
\text { of substrate } \\
\text { concentrations } \\
(0.2-0.5 \mathrm{mM} \\
\text { GSH })\end{array}$ & $\begin{array}{l}\text { Disconti- } \\
\text { nuity (mM } \\
\text { GSH) }\end{array}$ & $\begin{array}{c}K_{\mathrm{m}} \text { values }(\mathrm{mM}) \\
\text { in the high range } \\
\text { of substrate concen- } \\
\text { trations } \\
(0.6-2.0 \mathrm{mM} \text { GSH })\end{array}$ \\
\hline $\begin{array}{l}\text { Control large } \\
\text { intestines isolated on } \\
5 \text { dpi from infected } \\
\text { and untreated mice }\end{array}$ & 0.5 & 0.4 & 25.0 \\
\hline $\begin{array}{l}\text { Large intestines iso- } \\
\text { lated on } 5 \text { dpi from } \\
\text { infected and treated } \\
\text { with albendazole } \\
\text { mice }\end{array}$ & 0.7 & 0.7 & 3.1 \\
\hline
\end{tabular}

intestine caused an increase in the total GST activity and modified the GST kinetics of saturation with GSH in such a way that it caused a 12-fold decrease in the low $K_{\mathrm{m}}$ value and simultaneously, a 6-fold increase in the high $K_{\mathrm{m}}$ value, and about a 4-fold decrease in the point of discontinuity. In the mouse large intestine, infection with $T$. spiralis also caused an increase in the total GST activity. In addition, it caused a 4.6-fold increase in the low $K_{\mathrm{m}}$ value, whereas the high $K_{\mathrm{m}}$ value and the point of discontinuity remained unchanged. These results suggest that the presence of parasites and, probably, their excretory-secretory products released to the host intestines modify the kinetics of GST, altering its catalytic properties.

In summary, our investigations suggest that, in response to the infection, the mouse host initiates an increase in GST production. Our data show that GST activity in the intestines of the T. spiralis-infected mice increased, compared with the uninfected mice. Following albendazole treatment, this level was diminished but still significantly higher, compared with that in the intestines of the uninfected mice. Probably this reduction of GST production is caused by drug-induced impairment of parasites.

A biphasic Lineweaver-Burk plot of GST kinetics, with two apparent $K_{\mathrm{m}}$ values and a discontinuity, confirms that this enzyme belongs to allosteric enzymes. Such enzymes display a complex kinetic mechanism not easy to interpret. Usually allosteric enzymes consist of cooperative subunits and present a sigmoid shape of the graph of the reaction velocity (enzyme activity) as a function of substrate concentration. In allosteric enzymes, the binding of substrate to one active site may affect the properties of other active sites in the same enzyme molecule. A possible consequence of this interaction between subunits is that the oligomeric forms of the enzyme reveal kinetic substrate cooperation. Mammalian cytosolic GST is composed of two subunits and exists as a stable dimer. Interactions at the subunit interface play an important role in the stabilization of the dimeric structure of GST. Besides, the dimer is required to maintain functional conformations at the active site on each subunit and the nonsubstrate ligand binding site at the dimer interface (Hornby et al. 2002).

Based on our present research, we suppose that albendazole influences both the total activity and kinetics of the host cytosol- 
ic GST and probably causes changes in the quaternary structure of this important multifunctional enzyme during trichinellosis. However, the observed kinetic alternations of GST, which may indicate structural changes of this enzyme, are difficult to interpret.

In conclusion, because GST contributes to the host biochemical defence, we may hypothesize that, in addition to the direct antiparasitic activity of albendazole, it could affect the host defence mechanisms. In our opinion, this modulation of the host biochemical defence, following albendazole therapy, could impact the final efficacy of treatment of trichinellosis.

We are grateful to Prof. Krystyna Boczoń for her helpful suggestions and support during this study. The experiments carried out in this study comply with the current laws of Poland.

\section{References}

Derda M., Boczoń K., Wandurska-Nowak E., Wojt W. 2003: Changes in the activity of glutathione-S-transferase in muscles and sera from mice infected with Trichinella spiralis after treatment with albendazole and levamisole. Parasitol. Res. 89: 509-512.

Derda M., Wandurska-Nowak E., Boczoń K. 2001: Glutathione-S-transferase activity in mouse muscle during experimental trichinellosis. Wiad. Parazytol. 47: 227-232.

Habig W., JАковY W. 1981: Assays for differentiation of glutathione S-transferase. Methods Enzymol. 77: 398-405.

Hayes J., Flanagan J., Jowsey I. 2005: Glutathione transferases. Annu. Rev. Pharmacol. Toxicol. 45: 51-88.

Hornby J., Codreanu S., Armstrong R., Dirr H. 2002: Molecular recognition at the dimmer interface of a class $\mathrm{mu}$ glutathione transferase: role of a hydrophobic interaction motif in dimmer stability and protein function. Biochemistry 48: 14238-14247.

KöHLER P. 2001: The biochemical basis of anthelmintic action and resistance. Int. J. Parasitol. 31: 336-345.

LACEY E. 1988: The role of the cytoskeletal protein, tubulin, in the mode of action and mechanism of drug resistance to benzimidazoles. Int. J. Parasitol. 18: 885-936.

Lacey E. 1990: Mode of action of benzimidazoles. Parasitol. Today 6: 112-115.

Lowry O., Rosenbrough W., Farr A., Randall R. 1951: Protein measurements with the Folin phenol reagent. J. Biol. Chem. 193: 265-275.

OAKLEY A. 2005: Glutathione transferases: new functions. Curr. Opin. Struct. Biol. 15: 716-723.

Sheehan D., Meade G., Foley V., Dowd C. 2001: Structure, function and evolution of glutathione transferases: implications for classification of non-mammalian members of an ancient enzyme superfamily. Biochem. J. 360: 1-16.

Wilce M., PARKer M. 1994: Structure and function of glutathione S-transferases. Biochim. Biophys. Acta 1205: 1-18.

Wojtkowiak A., Boczoń K., Wandurska-Nowak E., Derda M. 2007: Evaluation of effects of albendazole on the kinetics of cytosolic glutathione transferase in skeletal muscles during experimental trichinellosis in mice. Parasitol. Res. 100: 647-651.

Wojtkowiak-Giera A., Wandurska-Nowak E., Michalak M., Derda M. 2011: Changes in the activity and kinetics of mouse intestinal glutathione transferase during experimental trichinellosis. Parasitol. Res. 108: 1309-1313.

Received 10 May 2012

Accepted 31 July 2012 